\title{
Fungal Cobalamin-independent methionine synthase: insights from the model organism, Neurospora crassa
}

\author{
Robert W. Wheatley*, Kenneth K. S. Ng and Manju Kapoor \\ Division of Biochemistry, Department of Biological Sciences, Faculty of Science, University of \\ Calgary, Calgary, AB, Canada T2N 1N4
}

*Corresponding author. E-mail: rob@wheatley.ca 


\begin{abstract}
Two families of methionine synthases, distinct in catalytic and structural features, have been encountered: MetH, the cobalamin-dependent enzyme and MetE, the cobalamin-independent form. The MetE family is of mechanistic interest due to the chemically challenging nature of the reaction and is a potential target for antifungal therapeutics since the human genome encodes only MetH. Here we report the identification, purification, and crystal structure of MetE from the filamentous fungus Neurospora crassa (ncMetE). ncMetE was highly thermostable and crystalized readily, making it ideal for study. Crystal structures of native ncMetE in complex with either $\mathrm{Zn}^{2+}$ or $\mathrm{Cd}^{2+}$ were solved at resolution limits of $2.10 \AA$ and $1.88 \AA$, respectively. The monomeric protein contains two domains, each containing a $(\beta \alpha)_{8}$ barrel core, and a long $\alpha$ helical segment spans the length of the protein, connecting the domains. $\mathrm{Zn}^{2+}$ bound in the $\mathrm{C}$ terminal domain exhibits tetrahedral coordination with the side chains of His 652 , Cys 654, Glu 676 and Cys 737. A $\mathrm{Cd}^{2+}$ replete structure revealed a supermetalated enzyme and demonstrated the inate flexibility of the metal binding site. An extensive analysis of sequence conservation within the MetE family identified 57 highly conserved residues and 60 additional residues that were conserved in all fungal sequences examined.
\end{abstract}

Keywords: Methionine synthase; MetE; Neurospora crassa; Metalloenzymes; Zinc; Cadmium. 


\section{Introduction}

Methionine synthases catalyzes the final step in the methionine biosynthetic pathway, namely the methylation of homocysteine using 5-methyltetrahydropteroyl-L-glutamate $\left(\mathrm{CH}_{3}-\mathrm{H}_{4} \mathrm{PteGlu}\right)$ as the methyl group donor. The importance of methionine in translation initiation and protein biogenesis, as a universal component of proteins and peptides as well as an essential amino acid in human and animal nutrition cannot be over-emphasized. Additionally, the methionine synthase reaction is at the junction of two metabolic networks, sulfur and one-carbon metabolism; methionine is the source of S-adenosylmethionine (SAM), the universal donor of methyl groups to numerous metabolites and cellular macromolecules. Two distinct classes of methionine synthases have been encountered: MetH, the cobalamin-dependent methionine synthases (EC 2.1.1.13), and the cobalamin-independent methionine synthase group, designated MetE (EC 2.1.1.14). The distribution of these enzymes varies through the biosphere, with animals only utilizing the cobalamin-dependent enzyme. Bacterial species and protozoan genomes encode both forms of this enzyme whereas fungal and plant species encode only the cobalamin-independent enzyme [1,2]. The two enzymes differ in their specificity for folate substrates. MetH is active with $\mathrm{CH}_{3}-\mathrm{H}_{4} \mathrm{PteGlu}_{1}$ [3], whereas MetE enzymes require at least a polyglutamate tail of two glutamate units: $\mathrm{CH}_{3}-\mathrm{H}_{4} \mathrm{PteGlu}_{2}$ [4]. The two enzymes are also characterized by distinct structural features. Enzymes from the MetH group typically have four distinct structural domains while enzymes from the MetE class are composed of two domainssimilar in sequence - a consequence of a presumed gene duplication event [5-7]. Crystal structures of cobalamin-independent methionine synthase from two bacterial species, Thermatoga maritima [7] and Streptococcus mutans [8], a plant, Arabidopsis thaliana [9], and a fungal species, the yeast Candida albicans [10] have been reported. The importance of MetE in metabolism is highlighted by the observation that it is a major cellular component in wild type E.coli grown in minimal medium, where it is estimated to be $\sim 3 \%$ of the soluble protein [11].

Neurospora crassa is a well characterized model filamentous fungus. In N. crassa, genetic analysis identified a putative cobalamin-independent methionine synthase encoded by the met 8 locus [12]; met-8 mutants are characterized by sulfur auxotrophy. The met8 locus (NCU 3 
06512.1) is homologous to the classical eukaryotic cobalamin-independent methionine synthase, with the best overall match of the translated sequence with the Aspergillus nidulans MetH/D. Several decades ago a decrease in MetE level was documented in N. crassa mycelium in the presence of choline in the growth medium [13]. This is presumably a result of feedback regulation. As choline biosynthesis depends on SAM as the methyl group donor, choline can be envisioned as a distant end-product of the biosynthetic pathway leading to the aspartate family of amino acids. At present this is the only documented mechanism of regulation of N.crassa MetE. Experiments in our laboratory, by probing immunoblots of cell extracts with Neurospora MetEspecific IgG, showed no noticeable effect of amino acids-including methionine —or heat treatment on the level of this enzyme in mycelium grown in minimal medium (Quimet and Kapoor, unpublished data). Different regulatory mechanisms are witnessed in other fungal species. Feedback inhibition and repression by the end product of the metabolic pathwaymethionine-are well documented. In Aspergillus nidulans, MetE gene expression is repressed by methionine and choline, and induced by homocysteine in the growth medium and by osmotic and oxidative stress [14]. In C. albicans, MetE is upregulated to a limited extent under hyperthermia and is developmentally regulated during transformation of the unicellular yeast phase to the hyphal state [15]. In Saccharomyces cerevisiae, methionine in the growth medium, as well as osmotic and oxidative stress elicit a reduction in the expression of MET6, the gene encoding MetE [16].

Methionine synthases are both directly and indirectly involved in the cellular stress response. The reaction product, methionine, can directly act to protect the cellular machinery from oxidative stress by acting as a sink for reactive oxygen species (ROS). A direct demonstration of the antioxidant defense by methionine residues was provided by experiments based on replacement of a large fraction of methionine residues in E. coli with norleucine - a sulfurless but isosteric analogue of methionine. The exposure of norleucine-containing cells to oxidative stress by treatment with oxidizing agents (e.g. $\mathrm{H}_{2} \mathrm{O}_{2}$ or ionizing radiation) resulted in increased lethality compared to the wild type methionine-containing cells [17]. Methionine residues in proteins are oxidized by ROS to give rise to methionine sulfoxide. The latter is converted 
efficiently to methionine by the action of another enzyme, methionine sulfoxide reductase, present in multiple isoforms in all eukaryotic and prokaryotic organisms [18]. The E.coli cobalamin-independent enzyme is inactivated by oxidation of a specific cysteine residue (Cys 645), positioned at a critical spot in close proximity to the catalytic site, thereby leading to methionine deficit [19]. As noted above, in C. albicans, MetE is upregulated by hyperthermia. The expression of methionine synthase gene in Hordeum vulgare (Barley) leaves was reported to be induced by a variety of abiotic stresses including exposure to light, high salinity, drought, cold stress and hydrogen peroxide [20]. Moreover, it has been observed that osmolite stress by sucrose results in increased transcription of the metS gene in Solanum tuberosum and Catharanthus roseus, but apparently without a corresponding change at the protein level [21], suggesting regulation at the translational level.

Methionine synthases also have a cellular role in protecting against homocysteine toxicity. Mutations or inhibition of methionine synthase activity lead not only to methionine auxotrophy but to accumulation of homocysteine, presumably derived from methionine through the SAM pathway. Homocysteine is highly toxic to the fungal cell as it interferes with biosynthesis of ergosterol, resulting in deleterious effects on cell membranes [22-24]. As the human genome encodes only the cobalamin-dependent methionine synthase and the fungi have the cobalaminindependent representative, the latter has been proposed as a potential target for antifungal drugs, against such pathogens as Cryptococcus neoformans [25] and C. albicans [26].

The reaction catalyzed by methionine synthases is chemically challenging, as it entails cleavage of a $\mathrm{C}-\mathrm{N}$ bond in the $\mathrm{CH}_{3}-\mathrm{H}_{4} \mathrm{PteGlu}$ substrate. The two distinct families of methionine synthases solve the problem in different ways. The more catalytically efficient MetH family uses cobalamin as the first recipient of the methyl group from $\mathrm{CH}_{3}-\mathrm{H}_{4} \mathrm{PteGlu}$, which is then transferred to homocysteine. This reaction is characterized by a turnover of $1128 / \mathrm{min}$ in the $E$. coli cobalamin-dependent enzyme [3]. In contrast, in the MetE family of enzymes, methylation of Hcy is catalyzed by a direct methyl transfer from the $\mathrm{CH}_{3}-\mathrm{H}_{4} \mathrm{PteGlu}$. This reaction is considerably slower and the cobalamin-independent MetE of E. coli exhibits a turnover number of 22.6/min [4]. Work to understand the challenging mechanism of cobalamin-independent 
methionine synthase is ongoing. Interest has focused on the $\mathrm{Zn}^{2+}$ ion positioned at the active site, which seems to have a role in activating the homocysteine substrate. Interestingly, this zinc ion is found to be mobile and to move towards homocysteine upon substrate binding [27-29]. However, in currently available MetE structures the zinc and homocysteine sulfur form a strong interaction $(\sim 2 \AA)$ that would most likely limit the ability of homocysteine to act as a nucleophile. Identifying the binding site for the $\mathrm{CH}_{3}-\mathrm{H}_{4} \mathrm{PteGlu}$ substrate has also been challenging. Initial structures from A. thaliana [9] and T. maritima [7] placed the folate methyl group greater than $7 \AA$ from the homocysteine sulfur, too distant to constitute a catalytically productive complex. Recently, a C. albicans structure was reported with the substrate, homocysteine, and the product, $\mathrm{H}_{4} \mathrm{PteGlu}_{3}$, brought in close proximity by a conformational change [29]. While site directed mutations suggested that the folate binding site was correctly identified, this structure (PDB 4QQU) actually places the two ligands in rather tight proximity, such that there would be insufficient space to accommodate a reactive methyl group.

As stated in the preceding, the investigation of fungal methionine synthases is of direct interest as a potential target for antifungal therapies. In addition, studies of MetE contribute to the ongoing investigation of cellular stress response, and to fundamental investigations of the role of zinc in catalysis. To further understand this family of enzymes, we extended the study of this enzyme to the model filamentous fungal species, Neurospora crassa. In this communication we present the purification and characterization of the $N$. crassa enzyme in its native state, the identity of the purified enzyme being confirmed by peptide fingerprinting analysis and catalytic activity assays. We report the crystallization and X-ray structure of wild type $N$. crassa MetE (ncMetE) complexed with $\mathrm{Zn}^{2+}$, and use a structure complexed with $\mathrm{Cd}^{2+}$ to investigate the elasticity of the metal binding site. Finally, we employ an extensive analysis of known MetE sequences and structures to examine structurally important features of this enzyme family..

\section{Material and Methods}

(6R,S)-5-methyl-5,6,7,8-tetrahydropteroyltri-y-L-glutamic acid-3HCl was purchased from Schircks Laboratories (Buechstrasse 10, CH8645 Jona, Switzerland). Homocysteine was a 
product of Sigma and Sequencing Grade Trypsin was obtained from Roche Applied Science. PEG 3350 and PEG 400 were purchased from Hampton Research. Homocysteine, dithiothreitol, ammonium bicarbonate and iodoacetamide were from Sigma. All other reagents were of the highest grade available and were obtained from standard commercial sources.

\section{Growth of N. crassa, Isolation and Purification of Methionine Synthase}

Cultures of a wild-type N. crassa strain (Fungal Genetics Stock Centre No. 262) were raised in Vogel's minimal medium, Vm [30] supplemented with $2 \%$ sucrose, for $14 \mathrm{~h}$ at $28{ }^{\circ} \mathrm{C}$ while shaking. Heat-shock treatment was administered at $48{ }^{\circ} \mathrm{C}$ for $1 \mathrm{~h}$ while shaking [31] and the mycelium was harvested by vacuum filtration, lyophilized and stored at $-20{ }^{\circ} \mathrm{C}$. Purification was performed at room temperature with protein fractions being stored on ice between purification steps. A FPLC system (Phamacia) was employed for all chromatography steps and fractionation was monitored by UV absorbance $(280 \mathrm{~nm})$ and conductivity measurements. Fractions containing ncMetE were identified using SDS-PAGE (10\% acrylamide). Protein concentration was determined using the Coomassie blue dye binding method (Protein Assay Dye Reagent, Biorad) with bovine serum albumin as the calibration standard.

For purification of ncMetE, 15 gm lyophilized mycelium was suspended in $240 \mathrm{~mL}$ Extraction

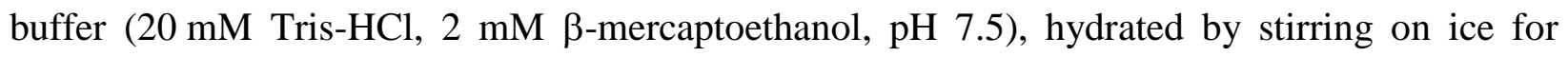
30 min, homogenized with a Potter-Elvehjem homogenizer, and finally stirred on ice for a further $30 \mathrm{~min}$. Insoluble material was removed by centrifugation at $9000 \mathrm{~g}$ for $45 \mathrm{~min}$. Next, to remove DNA and other material, protamine sulfate (12 $\mathrm{ml}$ of a $2 \%(\mathrm{w} / \mathrm{v})$ solution) was slowly added to the cell extract. Following stirring on ice for another $30 \mathrm{~min}$ the precipitate was removed by centrifugation at $9000 \mathrm{~g}$ for $30 \mathrm{~min}$. Finely ground PEG $8000(15 \% \mathrm{w} / \mathrm{v})$ was added to the supernatant over approximately $15 \mathrm{~min}$ while the extract was stirred on ice, and after complete dissolution of PEG, the extract was mixed for a further $30 \mathrm{~min}$. The precipitated protein fraction was removed by centrifugation at $9000 \mathrm{~g}$ for $30 \mathrm{~min}$ and Q-Sepharose FF matrix $(10 \mathrm{~mL})$ was mixed with the supernatant, at $4{ }^{\circ} \mathrm{C}$ for $10 \mathrm{~min}$. The beads were recovered by vacuum filtration, washed twice with $50 \mathrm{~mL}$ of the Extraction buffer and ncMetE was eluted with two $25 \mathrm{~mL}$ washes with $20 \mathrm{mM}$ Tris- $\mathrm{HCl}$ (pH 7.5), $250 \mathrm{mM} \mathrm{NaCl}$. The recovered protein 7 
solution $(50 \mathrm{~mL})$ was dialyzed overnight at $4{ }^{\circ} \mathrm{C}$ against $4 \mathrm{~L}$ of $20 \mathrm{mM}$ Tris- $\mathrm{HCl}(\mathrm{pH} 7.5)$ and then applied to a Cibacron Blue 3GA column (15 mL Sigma Cibacron Blue 3GA matrix in a Biorad $1.5 \times 15 \mathrm{~cm}$ Econo-Column), pre-equilibrated with the same buffer. Elution was performed with a $80 \mathrm{~mL}$ linear gradient of 0 to $1 \mathrm{M} \mathrm{KCl}$ at a rate of $2 \mathrm{~mL} / \mathrm{min} ; 2 \mathrm{~mL}$ fractions were collected and those containing ncMetE were pooled. Using centrifugal filter units (Amicon Centricon 20, $10000 \mathrm{MWL}$ ), the protein sample was concentrated to approximately $1 \mathrm{~mL}$ and then washed twice with $9 \mathrm{~mL}$ of $20 \mathrm{mM}$ Sodium Malonate (pH 5.2). The concentrated sample was applied to a $1 \mathrm{~mL}$ MonoS column (Pharmacia HR5/5) pre-equilibrated with the above Malonate buffer. The column was eluted with a $30 \mathrm{~mL}$ linear gradient from 0 to $200 \mathrm{mM} \mathrm{KCl}$ at a flow rate of $1 \mathrm{~mL} / \mathrm{min}$. Fractions $(1 \mathrm{~mL})$ enriched in ncMetE were pooled and the recovered protein $(\sim 4 \mathrm{~mL})$ was dialyzed overnight at $4{ }^{\circ} \mathrm{C}$ against $4 \mathrm{~L}$ of $20 \mathrm{mM}$ Tris- $\mathrm{HCl}(\mathrm{pH} 7.5)$. Next, the protein was applied to a $1 \mathrm{~mL}$ MonoQ column (Pharmacia HR5/5) pre-equilibrated with $20 \mathrm{mM}$ Tris $-\mathrm{HCl}(\mathrm{pH} 7.5)$ and eluted with a $30 \mathrm{~mL}$ gradient from 0 to $200 \mathrm{mM} \mathrm{KCl}$ at a flow rate of $1 \mathrm{~mL} / \mathrm{min}$. Fractions $(1 \mathrm{~mL})$ containing ncMetE were pooled and concentrated to $\sim 10 \mathrm{mg} / \mathrm{mL}$ (Amicon Centricon 20 Centrifugal Filter Units, 10000 MWL). After the initial concentration, the sample was rinsed twice with $10 \mathrm{~mL}$ of $20 \mathrm{mM}$ Tris- $\mathrm{HCl}(\mathrm{pH} 7.5)$ to remove $\mathrm{KCl}$. Aliquots of purified ncMetE were stored at $-70^{\circ} \mathrm{C}$. This 6-step procedure yielded a nearly homogeneous protein preparation. Alternatively ncMetE was isolated from normally grown, non-shocked cells but the yield from heat-shocked cells was higher with considerable improvement in purification/yield of the final product.

\section{Identification of ncMetE}

The identity of the purified protein was determined by MALDI-TOF mass spectrometric analysis at the Southern Alberta Mass Spectrometry Centre facility at the University of Calgary. A band of the purified protein was excised from a Coomassie blue-stained gel, washed twice in Milli-Q filtered water, twice with $50 \mathrm{mM}$ ammonium bicarbonate/50\% (v/v) acetonitrile and allowed to dry. Next the samples were reduced in $10 \mathrm{mM}$ DTT/100 mM ammonium bicarbonate, alkylated by treatment with $55 \mathrm{mM}$ iodoacetamide/100 $\mathrm{mM}$ ammonium bicarbonate and washed again with $100 \mathrm{mM}$ ammonium bicarbonate. The gel pieces were washed with acetonitrile and, after 
removing the latter, vacuum dried. Dehydrated gel pieces were re-swelled in ammonium bicarbonate buffer containing $12.5 \mathrm{ng} / \mu \mathrm{l}$ trypsin and incubated overnight at $37{ }^{\circ} \mathrm{C}$. Extracted peptides were identified from MS/MS spectral data using Mascot (Matrix Science, Boston, MA USA) with a multi-organism non-redundant protein database with trypsin specificity.

\section{Catalytic Activity and Thermal Stability}

Catalytic activity of purified ncMetE was determined using a fixed-time spectrophotometric assay [32]. Briefly, the assay mixture consisted of $10 \mathrm{mM} \mathrm{K}_{2} \mathrm{HPO}_{4} \mathrm{pH} 7.2,50 \mathrm{mM}$ Tris- $\mathrm{HCl} \mathrm{pH}$ 7.2, $100 \mathrm{mM} \mathrm{MgSO}$, $10 \mathrm{mM}$ DTT, $2 \mathrm{mM}$ Hcy, $66 \mu \mathrm{M}$ (6R,S)-5-methyl-5,6,7,8tetrahydropteroyltri-y-L-glutamic acid-3HCl, $100 \mu \mathrm{M} \mathrm{ZnCl}$ and $10 \mu \mathrm{g} / \mathrm{mL}$ ncMetE. After incubation at $35^{\circ} \mathrm{C}$ for $10 \mathrm{~min}$, the reaction was terminated by addition of the stop solution $(5 \mathrm{~N}$ $\mathrm{HCl}, 60 \%$ formic acid, $25 \%$ reaction volume). Controls were prepared with boiled enzyme (10 min) and found to contain no activity.

For assessment of thermal stability of the enzyme $0.5 \mathrm{~mL}$ aliquots of crude cell extract (prepared as in the protein purification up to and including the protamine precipitation step) were incubated at $65{ }^{\circ} \mathrm{C}$ for $10 \mathrm{~min}$, controls being incubated on ice for the same time period. The samples were centrifuged at $16000 \mathrm{~g}$ and $4{ }^{\circ} \mathrm{C}$ for $30 \mathrm{~min}$, the supernatant was retained, and the pelleted protein was resuspended in $0.5 \mathrm{~mL}$ of $20 \mathrm{mM}$ Tris, $\mathrm{pH} \mathrm{7.5,2} \mathrm{mM} \beta$-mercaptoethanol. Total protein content of the fractions was estimated employing the Coomassie dye binding method (Protein Assay Dye Reagent, Biorad) and the relative ncMetE content of each fraction was determined by SDS-PAGE (10\% acrylamide) analysis.

\section{Crystallization}

Commercial sparse matrix screens were used initially to evaluate crystallization conditions. The enzyme was observed to crystallize readily under a variety of conditions. Crystals appeared extremely rapidly (< 15 min) using a precipitant solution of $20 \%$ (wt/vol) PEG 3350 and 200 $\mathrm{mM} \mathrm{KNO}_{3}$. This condition served as the basis for subsequent optimization experiments. 
Diffraction quality crystals were grown at room temperature employing hanging drop vapor diffusion over $1 \mathrm{~mL}$ of precipitant solution in EasyXtal DG (Qiagen) 24-well plates. Drops ( 3 $\mu \mathrm{L})$ consisted of equal parts protein and precipitant solution. Zinc replete ncMetE crystals were obtained by mixing a protein solution containing $5 \mathrm{mg} / \mathrm{mL}$ ncMetE, $1 \mathrm{mM} \mathrm{ZnSO}{ }_{4}, 1 \mathrm{mM}$ DTT, and $20 \mathrm{mM}$ Tris- $\mathrm{HCl}(\mathrm{pH} 7.5$ ) with a precipitant solution containing 22\% (wt/vol) PEG 3350, $150 \mathrm{mM} \mathrm{KNO}_{3}, 1 \mathrm{mM}$ DTT, and $20 \%$ (vol/vol) glycerol. Cadmium replete ncMetE complexes were crystallized by mixing a solution containing $5 \mathrm{mg} / \mathrm{mL}$ MetE, $0.7 \mathrm{mM} \mathrm{CdCl}_{2}, 1 \mathrm{mM}$ TCEP, and $20 \mathrm{mM}$ Tris- $\mathrm{HCl}(\mathrm{pH} 7.5)$ with a precipitant solution containing $22 \%(\mathrm{wt} / \mathrm{vol})$ PEG 3350, $200 \mathrm{mM} \mathrm{KNO} 3,1 \mathrm{mM}$ TCEP and $20 \%$ (vol/vol) glycerol. As the precipitant solution contained $20 \%$ glycerol, a cryprotection step was not required.

\section{Data collection/Refinement}

Diffraction intensities were collected from single crystals at $100 \mathrm{~K}$ using synchrotron $\mathrm{x}$-ray sources $\left(\mathrm{Zn}^{2+}\right.$ replete crystal: Advanced Light Source beamline 8.3.1, $\mathrm{Cd}^{2+}$ replete crystal: Canadian Light Source beamline 08-ID-1). The data were processed and scaled using DENZO and SCALEPACK [33]. Phases for ncMetE were initially solved by molecular replacement with PHASER [34] using the structure of Arabidopsis thaliana MetE (1U1J) [9] as the search model (50\% sequence identity). All crystals were isomorphic to the initial ncMetE structure. Solvent structures were initially built with ARP/wARP [35]. The final models were constructed by iterative cycles of manual model building with COOT [36] and refinement with REFMAC [37] or PHENIX [38]. $\mathrm{Cd}^{2+}$ ion occupancies were refined with PHENIX, and, as these atoms displayed an oblong $2\left|\boldsymbol{F}_{\boldsymbol{o}}\right|-\left|\boldsymbol{F}_{\boldsymbol{c}}\right|$ electron density, anisotropic temperature factors were employed. Anomalous dispersion data was collected and anomalous difference maps were used to confirm the metal ion positions. The data from the $\mathrm{Cd}^{2+}$ replete structure was collected at a wavelength $(1.55 \AA)$ above the $\mathrm{Zn}^{2+}$ absorption edge and the high level of density (> 30 sigma) in the anomalous difference map confirmed that the active site contained $\mathrm{Cd}^{2+}$ and not $\mathrm{Zn}^{2+}$.

\section{Bioinformatics}

Multiple sequence alignments were used to study sequence conservation and identify highly conserved residues in the MetE family of proteins. MetE sequences were obtained using the 10 
ncMetE protein sequence as the query sequence in a BLAST [39] search of the NCBI nonredundant protein database. Out of a set of 1000 homologous proteins obtained from the BLAST search, 4 sequences with large insertions or deletions were discarded for a final dataset of 996 sequences. $\quad N$. crassa MetE is 796 amino acids in length and sequences in the final dataset ranged from 689 to 845 residues, the average being 765. This dataset was comprised of 166 fungal, 90 plant, and 732 bacterial sequences. ${ }^{1}$ Sequences were aligned with ClustalX 2.1[40] using default parameters, and residues that were conserved either among the fungi or among all analyzed MetE sequences were determined. BioPerl [41] scripts were used to automate sequence analysis.

While multiple sequence alignments are a common tool for identifying important amino acid residues, the usual challenge is obtaining accurate alignments from low homology data. The high sequence conservation of the MetE family presented an inverse problem. The high degree of conservation limited efforts to infer functional significance of amino acids through evolutionary conservation. For example, in a test alignment of 100 sequences, $26 \%$ of the residues were found to be universally conserved and thus a randomly selected residue would have a significant chance of appearing conserved with this dataset. We approached this problem through our extended analysis, utilizing nearly 1000 MetE sequences. The result was the identification of a limited set of 57 residues that were extremely highly conserved. This set is utilized in the following discussion.

Putative roles for amino acid residues were determined by using LigPlot+ [42] to catalogue currently known interactions. Specifically, residues in ncMetE that interact with the substrate (homocycteine and folate) where determined by homology with structures: 1U22, 3BQ5, 3BQ6, 1XDJ, 4L5Z, and 4QQU. Residues that formed or changed interactions between the N- and C-

\footnotetext{
${ }^{1}$ The remaining eight sequences included two Archaea and six Eukaryotes (four Amoebozoa, one Rhodophyta, and one Ichthyosporea species). Phylogenetic reconstructions (data not shown) show that the 8 non-plant, animal, or bacterial proteins were located scattered among the three main groups, as would be typical for horizontal gene transfer. 
terminal domains during the catalytic conformational change were identified by homology with structures 3PPG (open form) and 4QQU (closed form).

\section{PDB accession numbers}

The atomic coordinates and structure factors of the ncMetE complexed with $\mathrm{Zn}^{2+}(4 \mathrm{ZTX})$ and $\mathrm{Cd}^{2+}(4 \mathrm{ZTY})$ have been deposited in the Protein Data Bank.

\section{Results and Discussion}

\section{Heat Treatment}

We first became interested in ncMetE while studying the heat shock response of Neurospora crassa mycelium. An unknown band-subsequently identified as ncMetE-comprising a major component of the soluble heat-shocked mycelial extract was neither induced nor repressed by heat shock. Thermal stability of the then unknown protein was evaluated by heating the cell extracts at $65{ }^{\circ} \mathrm{C}$ for $10 \mathrm{~min}$. ncMetE was recovered in the soluble fraction after the heat treatment, and SDS-PAGE analysis indicated that this protein formed the primary component of this fraction (Supplementary Figure 1). Hence, ncMetE is among the most thermostable proteins of $N$. crassa, suggesting that it may have an important role in mycelium subject to hyperthermia.

Other fungal MetE are also reported to be remarkably thermostable, with a heat treatment of 55 ${ }^{\circ} \mathrm{C}$ for 5 min being used during the purification of MetE from C. albicans and S. cerevisiae. However, these treatments at a lower temperature $\left(55^{\circ} \mathrm{C}\right.$ instead of $65^{\circ} \mathrm{C}$ used with the $N$. crassa enzyme) produced less dramatic effects: $\sim 70 \%$ of the total protein in the cell extract remained soluble, instead of the $24 \%$ remaining with the heat treatment of ncMetE.

\section{Protein Purification and Identification}

To further study this then unknown protein, a six-step purification protocol described in the Methods section was developed. Overall yield from $15 \mathrm{~g}$ of lyophilized heat-shocked mycelium was $\sim 10 \mathrm{mg}$ of a highly pure, nearly homogeneous protein preparation. A summary of the ncMetE purification steps is shown in Supplementary Figure 2. As shown by the SDS-PAGE 
profile, the PEG step separated the ncMetE band from the heat shock proteins, while Cibacron Blue fractionation enriched the preparation in ncMetE. Ion-exchange chromatography on MonoS and finally MonoQ matrixes resulted in removal of all other contaminating proteins. Upon resolution by SDS-PAGE a clear single band, with no apparent contaminating proteins, was visualized in Coommassie Blue-stained gels. Analysis of the trypsin peptide fingerprinting data using Mascot (Matrix Science, Boston, MA USA) to search the multi-organism nonredundant protein database identified a match with Neurospora crassa (protein NCU06512.1): cobalamin-independent Methionine synthase (EC. 2.1.1.14) with a 39\% sequence coverage (Mowse score 274, Expect value $1.3 \times 10^{-21}$ ). Enzyme activity assays further confirmed that the purified sample was catalytically active and had MetE activity. The purified ncMetE was characterized by a turnover number of $\sim 3 \min ^{-1}\left(35^{\circ} \mathrm{C}\right)$. This value is comparable with the relatively slow rates recorded with orthologous enzymes, but lower than the rate reported for $S$. cerevisiae and C. albicans [43].

\section{Crystal Structures}

The ncMetE enzyme readily crystallized and produced high quality crystals. Statistics for data collection and refinement are presented in Table 1 . The crystal form has $\mathrm{P} 2{ }_{1}{ }_{2}{ }_{1} 2_{1}$ space group symmetry and one protein molecule per asymmetric unit. The unit cell dimensions were approximately $a=78 \AA, b=94 \AA, c=115 \AA$. The $\mathrm{Zn}^{2+}$ replete structure was refined to $2.10 \AA$ resolution while the $\mathrm{Cd}^{2+}$ replete structure was refined to $1.88 \AA$ A. Electron density was observed for a continuous trace of the entire peptide chain, excluding the initial methionine residue. The structures revealed a monomeric protein, approximately 80 x 65 x $50 \AA$ An size, with a compact and slightly oblong shape (Figure 1). The protein monomer consists of two approximately equal-sized domains, each with a $(\beta \alpha)_{8}$ barrel core, separated by a central cleft—30 Å deep, $10 \AA$ wide - extending approximately half way through the protein. The two domains are connected by an $\alpha$-helical structure (residues 373 to 418 ) which spans most of the length of the protein ( 70 $\AA$ ) and forms a supporting scaffold or connector. A short structure (residues 515 to 529) containing a $\beta$-hairpin extends from the $\mathrm{C}$-terminal domain and comprises part of the $\mathrm{N}$-terminal domain on the face on the central cleft. Four amino acids at the C-terminus (766 to 769) 
protrude away from the protein core forming a random coil 'tail' (Figure 1A). These residues do not appear to interact with the remainder of the protein. Instead, this tail interacts with a neighboring protein molecule through crystal packing. In solution, without the packing interactions, this tail may not form an ordered structure. A notable predominance of positive charges on both sides of the central cleft was also observed (Figure 4B), while the charge distribution on the surface of the remainder of the enzyme appears typical for a soluble protein.

\section{Comparison with Other MetE Enzymes}

MetE has now been crystallized from two fungal species, N. crassa (this communication) and $C$. albicans [10]. Supplementary Figure 3 shows the reconstructed phylogeny of a set of MetE proteins, showing that the enzymes crystallized from the two fungal species are not closely related. The tree indicates that MetE has a complicated evolutionary history. Interestingly, both the eukaryotic groups of enzymes (plants and fungi) cluster closer to those of bacterial proteins than to each other. The tree also shows that the currently known crystal structures from bacteria are part of one closely related group, but it also appears that there are other clusters of bacterial enzymes that have yet to be structurally characterized.

Despite the large evolutionary distance between the species with crystallized MetE proteins, structural alignments found that the overall fold is highly conserved. Comparisons using DALI [44] found ncMetE to be most similar to the fungal C. albicans enzyme with a RMSD of $1.3 \AA$ (4L6H). The next most similar structure was the plant-A. thaliana - enzyme (RMSD of $1.6 \AA$, $1 \mathrm{U} 1 \mathrm{H})$. The $N$. crassa enzyme differed only slightly more from the bacterial enzymes from $T$. maritima (RMSD of $1.7 \AA$, 1XPG) and S. mutans (RMSD of $1.8 \AA$, 3L7R). Notwithstanding the high homology, notable structural variations are observed between orthologous enzymes. For example, comparison of the $N$. crassa and $C$. albicans [10] $\mathrm{Zn}^{2+}$ replete enzymes show that many parts of the C-terminal face of the central cleft are disordered in the C. albicans structure (residues equivalent to 655-657, 677-684,701-707, and 739-741 in $N$. crassa), while these same regions are well defined in the $N$. crassa structure. Additionally, the domain connector (residues 373 to 418) of ncMetE is composed of 3 a-helices encompassing residues 374-393, 400-408, and 411-414, respectively. While a similar topology is witness in most C. albicans structures, 14 
considerable differences are evident among the structures from other species (Supplementary Figure 4). In many of the reported structures, the connector contains residues with high temperature factors, or completely undefined residues, suggestive of conformational flexibility. In contrast, the connector is well defined in the two ncMetE structures and has a low temperature factor. Additionally, whereas the ncMetE connector contains multiple potential trypsin digestion sites (e.g., at residues 378, 391, 396, 405), the entire ncMetE enzyme, including this region, was extremely stable to trypsin digestion (data not shown). This observation indicates that the conformational stability of the connector in the ncMetE structure is not an artifact of crystal packing.

In addition to the fold, the MetE family was also found to be highly conserved at the sequence level. A pairwise alignment of the $N$. crassa protein sequence with one of the structurally most distant proteins, that of T. maritima, still found a $41 \%$ sequence identity. In a multiple sequence alignments utilizing a large dataset—nearly 1000 MetE family sequences derived from 166 fungal, 90 plant, and 732 bacterial species - 57 residues were still identified as being100\% conserved. The location of these exceptionally conserved residues in the ncMetE structure is illustrated in Figure 2A (coloured blue) and listed in Figure 2B. The MetE protein sequence conservation in 166 fungal species was also determined. In total, 117 residues are conserved in the fungi, including the 57 universally conserved residues. The additional 60 residues conserved only in the fungal enzyme are indicated by green colour in Figure 2A. Overall, a vast majority of the conserved residues are located in the $\mathrm{C}$-terminal domain, rather than the $\mathrm{N}$-terminal domain. This conservation is also reflected in the fold, with, for example, DALI comparisons of the $N$. crassa and T. maritima $\mathrm{N}$-terminal domains finding an RMSD of $1.8 \AA$, while the C-terminal domains have a RMSD of only $1.2 \AA$. Among the conserved residues in the N-terminal domain, residues on the surface of the central cleft predominate (Figure 2A). 


\section{Metal Binding}

\section{$\mathrm{Zn}^{2+}$ complex}

The ncMetE enzyme crystallized in the presence of $\mathrm{Zn}^{2+}$ revealed a zinc binding site, located in the C-terminal domain and facing the central cleft (Figure 3A). The zinc exhibits tetrahedral coordination, interacting with the side chains of His 652, Cys 654, Glu 676, and Cys 737 (Table 2). His 652 is part of one of the $\beta$-strands that forms the core of the $(\beta \alpha)_{8}$ barrel, the remaining 3 residues are located in loops between the barrel $\beta$-strands and $\alpha$-helices. A tetrahedral $\mathrm{Zn}^{2+}$ coordination geometry characterized by four protein ligands (His, two Cys, and one Glu residue) has also been reported for T. maritima (3BQ6) and $C$. albicans (3PPG) enzymes. While in most enzyme families, such a site would be expected to be well preserved, in MetE, numerous variations have been observed. Structures with a distorted metal geometry, where an additional water ligand partially displaces the $\mathrm{Zn}^{2+}$ Glu ligand have been reported in C. albicans (3PPC) and S. mutans (3T0C). Additionally, one A. thaliana structure (1U1U) was reported with severely distorted coordination geometry. While in some enzyme classes the $\mathrm{Zn}^{2+}$ coordinating amino acids can vary (i.e., Cys can substitute for His), our sequence analysis shows that in MetE these residues are $100 \%$ conserved (indicated by stars in Figure 2B).

Differences between ncMetE and the tetrahedral coordination sites in the orthologous enzymes are also observed. Compared to C. albicans (3PPG), the side chain conformations for both Glu 676 and Cys 654 side chain are altered, with, for example the $\chi_{1}$ dihedral of Cys 654 rotating $86^{\circ}$. The distance from $\mathrm{Zn}^{2+}$ to Glu 676 also decreases, specifically the Glu $676 \mathrm{C} \alpha-\mathrm{Zn}^{2+}$ distance decreases $0.7 \AA$. Finally, as discussed above, three residues after Cys 654 are undefined in the electron density for the $C$. albicans structure, but clearly discernable, albeit with higher than average temperature factors, in ncMetE. The dynamic nature of the metal binding site has been linked to enzyme function, with changes in the metal position and coordination number proposed to occur during catalysis $[8,27,28]$. Variations in the protein $-\mathrm{Zn}^{2+}$ interactions as revealed by the ncMetE structure indicate a significant diversity in the underlying structural energetics of the metal binding site. In turn, these observations indicate a diversity in the mechanisms of MetE family of enzymes with respect to the $\mathrm{Zn}^{2+}$ positional change that occurs during catalysis. 16 


\section{$\mathrm{Cd}^{2+}$ complex}

To further characterize the dynamic nature of the metal binding site, we crystallized ncMetE complexed with cadmium - a highly cytotoxic heavy metal and an inducer of oxidative stress. A previous report in the literature suggests that $\mathrm{Cd}^{2+}$-complexed MetE is largely inactive (González, Peariso et al. 1996). We found the $\mathrm{Cd}^{2+}$ ion replaced the $\mathrm{Zn}^{2+}$ ion in the active site (Figure 3B). The slightly larger $\mathrm{Cd}^{2+}$ ion was accommodated in the binding site without any gross changes to the overall fold and the RMSD between the two structures was only $0.2 \AA$ over all amino acids. However, significant changes were noted around the metal binding site. First, in the $\mathrm{Cd}^{2+}$ substituted enzyme the active site $\mathrm{Cd}^{2+}$ is a member of a 4 atom $\mathrm{Cd}^{2+}$ cluster (Figure $3 \mathrm{C}$ ), the $\mathrm{Cd}^{2+}$ ions are labeled $\mathrm{Cd} 1$ to $\mathrm{Cd} 4$ ). Bridging the $\mathrm{Cd}^{2+}$ cations are either water molecules or the side chains of Glu 676, Cys 654, or Cys 737. The distance between Cd 2 and Cd 3 is larger than the rest (4.6 ̊ compared to 3.8 to $4.2 \AA$ ) and in this case there are two water molecules positioned such that they could act as an extended bridge between these two cations (Figure 3C). The electron density indicates that the Cys 737 side chain adopts two main conformations, the first being similar to the conformation in the $\mathrm{Zn}^{2+}$ structure $\left(\chi_{1}=-160^{\circ}\right)$ and the second being rotated towards Glu $676\left(\chi_{1}=-35^{\circ}\right)$. The additional cluster ions explain this conformational change, as the rotation from the $\mathrm{Zn}^{2+}$ position moves the side chain $0.7 \AA$ away from the active site cation (Cd 1) but $0.2 \AA$ closer to Cd 3 (Figure 3C).

Secondly, in the $\mathrm{Cd}^{2+}$ replete structure, the electron density clearly showed the presence of an additional ligand coordinating the active site cation (Figure 3B). Care was taken in modeling this ligand, and components of the crystallization medium such as $\mathrm{NO}^{3-}$ ion or glycerol were considered. Although the electron density signal appeared somewhat larger than typical for a water molecule, this ligand had the overall best fit. The additional ligand likely reflects the larger size of $\mathrm{Cd}^{2+}$ compared to $\mathrm{Zn}^{2+}$, which in turn leads to higher coordination numbers [45]. Depending on the Cys 737 conformation considered, there are two possible $\mathrm{Cd}^{2+}$ coordination geometries. In the first Cys 737 conformation, the addition of the ligand produces little change in the position of the protein ligands around the metal, and these four ligands maintain essentially 
the same tetrahedral geometry observed in the $\mathrm{Zn}^{2+}$ structure. In the second Cys 737 conformation, the five metal ligands approach a triangular bipyramidal structure.

Most significantly, the $\mathrm{Cd}^{2+}$ replete structure also revealed conformational flexibility in the metal binding site. To accommodate the larger metal ion, the metal coordination distances increased. Little strain was observed in metal binding, as the coordination distances were approximately optimal for $\mathrm{Cd}^{2+}$ (Table 2). For His 652, Cys 654, and Cys 737, the metal coordination distances increase $\sim 0.2$. A more pronounced change is evident for Glu 676, with the side chain displaced $0.5 \AA$ further from the metal compared to the $\mathrm{Zn}^{2+}$ enzyme. The conformation of the Glu 676 side chain also differed from that in the $\mathrm{Zn}^{2+}$ replete structure, resulting in a displacement of the carboxyl oxygen by approximately $1.6 \AA$ from its position with the natural metal. In this new position the oxygen still maintains its interaction with the active site cation, but also interacts with $\mathrm{Cd} 3$ and $\mathrm{Cd} 4$. This movement models that which is predicted during catalysis, where the Glu 676 is displaced from binding the active site metal by the incoming homocysteine.

For $\mathrm{Zn}^{2+}$ to move from the basal position (Figure $3 \mathrm{~A}$ ) to the homocysteine bound position, it must pass through a "pore" formed by His 652, Cys 654, and Cys 737 (first conformation). Structural alignments of the $\mathrm{Zn}^{2+}$ and $\mathrm{Cd}^{2+}$ replete models show that the positions of His 652 and Cys 654 are essentially unchanged. The $\mathrm{Cd}^{2+}$ ion is displaced approximately $0.5 \AA$ laterally towards Cys 737, and to accommodation the larger ion, the Cys thiolate group moves about 0.9 $\AA$ away from its position in the $\mathrm{Zn}^{2+}$ structure. The Cys $737 \chi_{1}$ angle remains essentially unchanged, as the movement is primarily due to changes in the protein backbone around this residue. The relative stability of the Cys 737 dihedral is noteworthy and likely indicates a strong H-bond interaction from the thiolate sulfur to the Gly 738 backbone amide. It has been proposed that the movement of the $\mathrm{Zn}^{2+}$ during catalysis includes contributions from both structural changes in the metal binding site brought about by substrate bindings [28], and the intrinsic dynamic nature of the site $[8,28]$. In our data, we find that, without a substrate present, the protein fold can allow significant changes in the Cys 737 backbone position but not side chain conformation. 


\section{Active Site}

Homocysteine has been found to bind in the active site on the central cleft, adjacent to the $\mathrm{Zn}^{2+}$ [7]. The homocysteine sulfur is positioned to interact with the $\mathrm{Zn}^{2+}$, located in a similar position in the active site as the water ligand in the $\mathrm{Cd}^{2+}$ replete structure (Figure 3B). Homology with homocysteine replete structures identified 9 residues that function in homocysteine binding, which are indicated in Figure 2B. Of these 7 were $100 \%$ conserved among the 996 sequences we examined. Three of these conserved residues - Ser 443, Glu 494, and Asp 609-form hydrogen bonds with the amine and carboxylic acid groups of the substrate, while Met 500 sandwiches the substrate thiol group between its sulfur and the catalytic zinc. Two glycine residues (Gly 442 and Gly 738) are also part of the conserved group, and it is apparent that Gly has been selected due to its compact size, as a hypothetical alanine substitution would produce clashes. In the case of Gly 783, the additional methyl group would sterically interfere with the substrate carboxyl group binding, while with Gly 442 this group could interfere with the substrate amino and carboxyl groups, in addition to packing of Met 500. The final conserved residue is Lys 740 which forms part of the substrate binding site, interacting with the substrate head groups through packing interactions. Comparison with the $C$. albicans enzyme shows that this side chain is undefined in the open state, but becomes ordered and interacts with the substrate in the closed state. However, in ncMetE, this side chain is defined in the open state, but positioned such that it must undergo a conformation change before the substrate binding interaction is formed.

The second substrate, $\mathrm{CH}_{3}-\mathrm{H}_{4} \mathrm{PteGlu}$, is a large molecule. Initial structures from A. thaliana [9], T. maritima [7], and C. albicans [28]found this molecule to bind with the folate motif stacking over Trp-571 (100\% conserved) and the polyglutamate tail extending up the N-terminal side of the central cleft. However, these structures were not compatible with a catalytically active enzyme, as the distance between the methyl group of $\mathrm{CH}_{3}-\mathrm{H}_{4} \mathrm{PteGlu}$ and the homocysteine sulfur was greater than $7 \AA$. Recently, a structure with the $C$. albicans enzyme [29] demonstrated the closure of the central cleft, and in this new conformation, the two substrates are in positions that would be compatible with catalysis. In this closed conformation, the C-terminal side of the central cleft also interacts with the negatively charged $\mathrm{CH}_{3}-\mathrm{H}_{4} \mathrm{PteGlu}_{3}$ polyglutamate tail. This 
binding site is roughly denoted by the large area of positive charge on C-terminal side of the central cleft as depicted in Figure 1B. The C. albicans structure allows the identification of 20 residues that bind this substrate (Figure 2B, Figure 4), of which 8 are universally conserved. Notably, 5 out of 8 of the universally conserved residues are positively charged. The $\mathrm{N}$-terminal domain component of the binding site is predominately formed from the $\beta$-hairpin structure (residues 515 to 529) that extends from the C-terminal domain. The remaining $\mathrm{N}$-terminal interactions are formed by Asn120 and His 122, of with His 122 universally conserved.

Structural bioinformatics studies comparing known MetE structures found notable conformational differences in the part of the folate polyglutamate binding site on the C-terminal face of the central cleft. This region, represented by residues $448-463$ of ncMetE consists of an $\alpha$-helix (residues 448-459) followed by a loop (residues 460-463), with the $\alpha$-helix forming the top surface of the central cleft (Figure 4). In N. crassa, residues in this region have a temperature factor above the average for the entire protein, but remain reasonably well defined in the electron density map. This region is also reasonably well defined in most of the C. albicans and T. maritima structures, although there is some variability in this region among reported structures of the same species, as shown in Supplementary Figure 5. In comparison, this structure is either partially or completely undefined in the S. mutans and A. thaliana structures.

This cleft structure contains two residues that are conserved in all MetE sequences examined (Arg 451 and Arg 454 in N. crassa). These residues contribute to the positively charged surface in this region of the central cleft (Figure 1B). In the C. albicans closed conformation structure (4QQU), the homologous residues interact with the first two glutamate molecules of the $\mathrm{H}_{4} \mathrm{PteGlu}_{3}$ polyglutamate tail. Lys 459 is also a part of this structure and is universally conserved in the fungal dataset. The side chain of this residue is not resolved in the electron density of the $C$. albicans closed conformation structure (4QQU). However, it is partially resolved in the $N$. crassa structure and the electron density indicates that the side chain extends towards the central cleft. This residue likely functions to bind folate molecules with a polyglutamate tail greater than 3 residues long. Fungal MetE has been found to be active with 
polyglutamate tails of at least 4 residues in length [43]. The presence of the highly conserved folate-binding residues in this region suggests that the polyglutamate binding function is conserved even among those species in which this structure is largely undefined. This observation, in turn, implies that during catalysis in some species this region undergoes a conformational change from a nearly disordered state to that forming the observed substrate binding site.

Finally, structural analysis and site directed mutagenesis indicate that His 705 would act as a key catalytic acid, protonating the folate substrate through a water intermediate [29]. As expected for such a role, this residue is universally conserved in the sequences analyzed. The side chain of this residue is undefined in many $C$. albicans structures, but defined in the closed conformation structure [29]. In the ncMetE open conformation structures this residue is defined and already has a conformation similar to that which appears required for catalysis.

\section{Conformational change}

In examining the domain closure of MetE, it was found that both domains act as rigid bodies, and closure involves a rotation around an axis that is slightly off parallel from a plane through the central cleft [29]. The residues that are in contact between the domains are identified in Figure 2. In the open form, 41 residues have been found to make interdomain contacts. These residues are of interest as they form an interface dynamic enough to propagate the conformational change. Four residues-Pro 529, Trp 571, Arg 575, and Glu 615-were identified as highly conserved, however Trp 571 is a key residues in folate binding, and it also interacts with Glu 615 and Pro 529. In contrast, Arg 575, part of the C-terminal domain, has a location far from the active site and interacts with the $\mathrm{N}$-terminal domain through its backbone atoms This residue is also part of a cluster of 4 highly conserved residues - the other members being Asp 535, Asp 577, and Gln 586 - that are located almost directly below the central cleft and form complex network of interactions among themselves and with the connector that spans the length of the protein and joins the two domains (Figure 5) A second cluster of highly conserved residues, located at the C-terminal end of the connector, consists of the connector residue Arg 416, and two other residues, Asp 671 and Arg 423, which interact with Arg 416. As 21 
it is difficult to postulated any direct catalytic role for these highly conserved residues remote from the active site, their location suggests these residues have an important function in forming the dynamic interface involved in domain closure. Comparing the open and closed $C$. albicans structures [29] show the complex network of interactions formed by these residues undergo subtle but numerous changes upon domain closure.

In the closed form 28 residues form new contacts and six residues, making domain contacts in the open form, were no longer identified as part of the contact region (Figure 2). Four highly conserved residues-His 122, Arg 525, Tyr 655, His 705-form contacts when the domains close. His 705 is the catalytic acid and Arg 525 also functions in folate binding. In C. albicans His 122 and Tyr 655 have been studied for their role in the conformational change, and have been found to be important for enzyme activity [29]. Most of the new interdomain contacts occur in the half of the central cleft not found to function in folate binding (Figure 6A). In the $\mathrm{N}$-terminal domain, this region is comprised primarily of residues in the peptide between Gly 100 and Lys 125. In the middle of this region is a loop that extends above the central cleft (residues 99-110 in ncMetE). Two residues (Asn 102 and Asp 107) located towards the top of the loop with their side chains extending towards the central cleft to be conserved among all the fungal species, but not among MetE enzymes of other eukaryotic or prokaryotic species. After domain closure[29], Asp 107 would form ionic interactions with Arg 708 (conserved in all fungi) and Asn 102 would be located such that it could H-bond with the backbone of Val 709. As this interaction does not involve the side chain, there is no requirement for Val 709 to be conserved, and the sequence analysis indicated that it was not. These interactions suggest that in the fungi at least part of the loop structure is involved in stabilizing the closed conformation. As these residues are conserved only among the fungi, a difference between fungal and the other genera is apparent.

This loop is also notable for variation in length between species (Figure 6B). Among the currently available structures, this region is the shortest in T. maritima while the loops of $S$. mutans and A. thaliana are next in length. Finally, the loops visualized in the two fungal structures are the longest, with that in $C$. albicans extending considerably further away from the 22 
enzyme than the $N$. crassa loop (> $8 \AA$ ). The data from the crystal structures discussed above would suggest that the loop is the shortest in bacteria. However, the sequence alignment showed that in some bacterial species this loop can be quite long (e.g. 28 amino acid long in Rhodopseudomonas palustris and other species). As the corresponding loop of some bacterial species is histidine rich (e.g. HGVHHHH in Afipia broomeae), it is tempting to speculate that it could furnish a potential binding site for additional $\mathrm{Zn}^{2+}$ ions and may perform a regulatory function. This loop is also of note in fungal enzymes because only after mutating three residues of this loop that crystals of the C. albicans MetE could be obtained [10]. The shorter $N$. crassa loop, compared to that of $C$. albicans, may help explain why the otherwise similar C. albicans enzyme crystallizes less readily.

In conclusion, the study of cobalamin-independent methionine synthases was extended to the model organism $N$. crassa. Herein, we report the identification and purification of this enzyme in its native state. The purified protein crystallized readily and yielded a high quality structure with all but the initial methionine residue being defined in the electron density. The $\mathrm{Zn}^{2+}$ binding site was found to be composed of His 652, Cys 654, Glu 676, and Cys 737, binding the metal with a tetrahedral coordination geometry that showed conformational differences compared to previously known structures. $\mathrm{A} \mathrm{Cd}^{2+}$ replete structure revealed a supermetalated enzyme and demonstrated the inate flexibility of the metal binding site, showing, among other changes, that the protein fold can accommodated changes in the position of Cys 737 . An extensive analysis of sequence conservation within the MetE family identified 57 highly conserved residues and 60 additional residues that were conserved in all fungal sequences examined. These residues are discussed within the context of ligand binding and confirmation change. This analysis presents a comprehensive, global view of the MetE family of enzymes. 


\section{Abbreviations}

Hcy, L-homocysteine; 5- $\mathrm{CH}_{3}-\mathrm{H}_{4} \mathrm{PteGlu}, \quad(6 S)-\mathrm{N} 5$-methyl-5,6,7,8-tetrahydropteroylglutamate; $\mathrm{H}_{4}$ PteGlu, 5,6,7,8-tetrahydropteroylglutamate; DTT, dithiothreitol; $\quad$ TCEP, $\quad \operatorname{tris}(2-$ carboxyethyl)phosphine; MetE, cobalamin-independent methionine synthase; ncMetE, Neurospora cobalamin-independent methionine synthase (EC. 2.1.1.14); met-8, locus NCU06512.1, linkage group III, encoding Neurospora cobalamin-independent methionine synthase; RMSD, root-mean squared deviation

\section{Acknowledgements}

This work was supported in its initial stages by Discovery Grants from the Natural Sciences and Engineering Research Council (NSERC) of Canada to MK and to KN. We are grateful to Loeke Janzen for excellent technical assistance during the course of this study. X-ray diffraction data were measured at beamline 08-ID-1 of the Canadian Light Source (CLS), which is supported by the Natural Sciences and Engineering Research Council of Canada, the National Research Council Canada, the Canadian Institutes of Health Research, the Province of Saskatchewan, Western Economic Diversification Canada, and the University of Saskatchewan.

\section{Notes}

The authors declare no competing financial interest. 


\section{References}

[1] J.C. Gonzalez, R.V. Banerjee, S. Huang, J.S. Sumner, R.G. Matthews, Biochemistry 31 (1992) 6045-6056.

[2] S. Ravanel, M.A. Block, P. Rippert, S. Jabrin, G. Curien, F. Rébeillé, R. Douce, Journal of Biological Chemistry 279 (2004) 22548-22557.

[3] R.V. Banerjee, V. Frasca, D.P. Ballou, R.G. Matthews, Biochemistry 29 (1990) 11101-11109.

[4] J.C. González, K. Peariso, J.E. Penner-Hahn, R.G. Matthews, Biochemistry 35 (1996) 1222812234.

[5] C.W. Goulding, D. Postigo, R.G. Matthews, Biochemistry 36 (1997) 8082-8091.

[6] M.L. Ludwig, R.G. Matthews, Annual Review of Biochemistry 66 (1997) 269-313.

[7] R. Pejchal, M.L. Ludwig, PLoS Biol 3 (2004) e31.

[8] T.-M. Fu, J. Almqvist, Y.-H. Liang, L. Li, Y. Huang, X.-D. Su, Journal of Molecular Biology 412 (2011) 688-697.

[9] J.-L. Ferrer, S. Ravanel, M. Robert, R. Dumas, Journal of Biological Chemistry 279 (2004) 4423544238.

[10] D. Ubhi, K.L. Kavanagh, A.F. Monzingo, J.D. Robertus, Archives of Biochemistry and Biophysics 513 (2011) 19-26.

[11] C.D. Whitfield, E.J. Steers, H. Weissbach, Journal of Biological Chemistry 245 (1970) 390-401.

[12] E. Burton, J. Selhub, W. Sakami, Biochemical Journal 111 (1969) 793-795.

[13] E.G. Burton, R.L. Metzenberg, Archives of Biochemistry and Biophysics 168 (1975) 219-229.

[14] M.M. Kacprzak, I. Lewandowska, R.G. Matthews, A. Paszewski, Biochemical Journal 376 (2003) 517-524.

[15] E. Burt, C. O'Connor, B. Larsen, Mycopathologia 147 (1999) 13-20.

[16] C. Godon, G. Lagniel, J. Lee, J.-M. Buhler, S. Kieffer, M. Perrot, H. Boucherie, M.B. Toledano, J. Labarre, Journal of Biological Chemistry 273 (1998) 22480-22489.

[17] S. Luo, R.L. Levine, The FASEB Journal 23 (2009) 464-472.

[18] H. Weissbach, L. Resnick, N. Brot, Biochimica et Biophysica Acta (BBA) - Proteins and Proteomics 1703 (2005) 203-212.

[19] E.R. Hondorp, R.G. Matthews, Journal of Bacteriology 191 (2009) 3407-3410.

[20] Y. Narita, H. Taguchi, T. Nakamura, A. Ueda, W. Shi, T. Takabe, Plant Science 167 (2004) 10091016.

[21] M. Zeh, G. Leggewie, R. Hoefgen, H. Hesse, Plant Mol Biol 48 (2002) 255-265.

[22] H. Jakubowski, CMLS, Cell. Mol. Life Sci. 61 (2004) 470-487.

[23] H. Hatanaka, N. Ariga, J. Nagai, H. Katsuki, Biochemical and Biophysical Research Communications 60 (1974) 787-793.

[24] L.W. Parks, W.M. Casey, Annual Review of Microbiology 49 (1995) 95-116.

[25] R.C. Pascon, T.M. Ganous, J.M. Kingsbury, G.M. Cox, J.H. McCusker, Microbiology 150 (2004) 3013-3023. 
[26] H.S. Suliman, D.R. Appling, J.D. Robertus, Archives of Biochemistry and Biophysics 467 (2007) 218-226.

[27] M. Koutmos, R. Pejchal, T.M. Bomer, R.G. Matthews, J.L. Smith, M.L. Ludwig, Proceedings of the National Academy of Sciences 105 (2008) 3286-3291.

[28] D. Ubhi, G. Kago, A.F. Monzingo, J.D. Robertus, Journal of Molecular Biology 426 (2014) 18391847.

[29] D.K. Ubhi, J.D. Robertus, Journal of Molecular Biology 427 (2015) 901-909.

[30] H.J. Vogel, Microbial Genetics Bulletin 13 (1956) 42-43.

[31] M. Kapoor, J. Lewis, Canadian Journal of Microbiology 33 (1987) 162-168.

[32] J.T. Drummond, J. Jarrett, J.C. Gonzalez, S. Huang, R.G. Matthews, Analytical Biochemistry 228 (1995) 323-329.

[33] Z. Otwinowski, W. Minor, Methods in Enzymology 276 (1997) 307-326.

[34] A.J. McCoy, R.W. Grosse-Kunstleve, P.D. Adams, M.D. Winn, L.C. Storoni, R.J. Read, Journal of Applied Crystallography 40 (2007) 658-674.

[35] G. Langer, S.X. Cohen, V.S. Lamzin, A. Perrakis, Nature Protocols 3 (2008) 1171-1179.

[36] P. Emsley, K. Cowtan, Acta Crystallographica D60 (2004) 2126-2132.

[37] G.N. Murshudov, A.A. Vagin, E.J. Dodson, Acta Crystallographica D53 (1997) 240-255.

[38] P.D. Adams, P.V. Afonine, G. Bunkóczi, V.B. Chen, I.W. Davis, N. Echols, J.J. Headd, L.-W. Hung, G.J. Kapral, R.W. Grosse-Kunstleve, A.J. McCoy, N.W. Moriarty, R. Oeffner, R.J. Read, D.C. Richardson, J.S. Richardson, T.C. Terwilliger, P.H. Zwart, Acta Crystallographica D66 (2010) 213-221.

[39] S.F. Altschul, T.L. Madden, A.A. Schäffer, J. Zhang, Z. Zhang, W. Miller, D.J. Lipman, Nucleic Acids Research 25 (1997) 3389-3402.

[40] M.A. Larkin, G. Blackshields, N.P. Brown, R. Chenna, P.A. McGettigan, H. McWilliam, F. Valentin, I.M. Wallace, A. Wilm, R. Lopez, J.D. Thompson, T.J. Gibson, D.G. Higgins, Bioinformatics 23 (2007) 29472948.

[41] J.E. Stajich, D. Block, K. Boulez, S.E. Brenner, S.A. Chervitz, C. Dagdigian, G. Fuellen, J.G.R. Gilbert, I. Korf, H. Lapp, H. Lehväslaiho, C. Matsalla, C.J. Mungall, B.I. Osborne, M.R. Pocock, P. Schattner, M. Senger, L.D. Stein, E. Stupka, M.D. Wilkinson, E. Birney, Genome Research 12 (2002) 1611-1618.

[42] R.A. Laskowski, M.B. Swindells, Journal of Chemical Information and Modeling 51 (2011) 27782786.

[43] H.S. Suliman, G.M. Sawyer, D.R. Appling, J.D. Robertus, Archives of Biochemistry and Biophysics 441 (2005) 56-63.

[44] L. Holm, S. Kaariainen, P. Rosenstrom, A. Schenkel, Bioinformatics 24 (2008) 2780-2781.

[45] T. Dudev, C. Lim, Chemical Reviews 114 (2014) 538-556.

[46] X. Robert, P. Gouet, Nucleic Acids Research 42 (2014) W320-W324. 
Table 1. Crystallographic data collection and refinement statistics. Numbers in parentheses refer to the highest resolution shell.

Data Collection Statistics

$$
\mathrm{Zn}^{2+} \text { Complex } \quad \mathrm{Cd}^{2+} \text { Complex }
$$

$\begin{array}{lll}\begin{array}{l}\text { Wavelength }(\AA) \\ \text { Space Group }\end{array} & 1.28 & 1.55 \\ \text { Unit Cell } & \mathrm{P} 2{ }_{1}{ }_{1} 2_{1} & \mathrm{P} 2{ }_{1}{ }_{1}{ }_{1} \\ \quad & & \\ \quad a, b, c(\AA) & 78.3,94.6,114.9 & 78.0,95.2,115.12 \\ \quad \alpha, \beta\left({ }^{\circ}\right) & 90,90,90 & 90,90,90 \\ \text { Resolution Range }(\AA) & 60.0-2.10 & 39.02-1.88 \\ & (2.18-2.10) & (1.92-1.88) \\ \text { Unique Reflections } & 49989(4718) & 70184(4416) \\ \text { Completeness }(\%) & 98.8(94.9) & 99.7(98.4) \\ \text { Redundancy } & 12.2(6.6) & 7.0(6.6) \\ \mathrm{R}_{\text {merge }} & 0.064(0.25) & 0.122(1.012) \\ \text { Average }(I / \sigma(I)) & 39.7(5.8) & 11.7(1.8)\end{array}$

\section{Refinement Statistics}

$\begin{array}{lll}\text { Resolution Range }(\AA) & 60.0-2.10 & 39.0-1.88 \\ & (2.15-2.10) & (1.90-1.88) \\ \text { Number of reflections } & 47388(3514) & 70059(4330) \\ \begin{array}{l}\text { Number of atoms } \\ \quad \text { Total }\end{array} & 6847 & 6936 \\ \quad \text { Protein } & 6089 & 6089 \\ \quad \text { Solvent } & 729 & 813 \\ \quad \text { Heterogen } & 29 & 34 \\ \mathrm{R}_{\text {free }} \text { set size } & 2545(186) & 6698(192) \\ \mathrm{R}_{\text {work }} & 0.163(0.191) & 0.157(0.246) \\ \mathrm{R}_{\text {free }} & 0.217(0.249) & 0.202(0.288) \\ \text { Average B-factor }\left(\AA^{2}\right) & & \\ \quad \text { Protein } & 28 & 26 \\ \quad \text { Solvent } & 37 & 36 \\ \quad \text { Active site metal } & 41 & 28 \\ \quad 3 \text { Cd }{ }^{2+} \text { cluster ions } & - & 46 \\ \text { Deviations from ideal geometry (RMS) } & \\ \quad \text { Bond length }(\AA) & 0.008 & 0.008 \\ \quad \text { Bond angles }\left({ }^{\circ}\right) & 1.007 & 1.023\end{array}$

PDB ID

4ZTX

4ZTY 
Table 2. Metal binding coordination distances. The effect of the active site metal on coordination distances $(\AA)$ to the divalent cation $\left(\mathrm{M}^{2+}\right)$. For $\mathrm{Cd}^{2+}$ cluster ions, the distance from the ion to the closest metal binding site ligand is listed.

\begin{tabular}{llll} 
& $\mathrm{Zn}^{2+}$ & $\mathrm{Cd}^{2+}$ & Change \\
\hline Active Site Metal & & & \\
His 652- $\mathrm{M}^{2+}$ & 2.04 & 2.30 & 0.26 \\
Cys 654- $\mathrm{M}^{2+}$ & 2.35 & 2.50 & 0.15 \\
Cys 737- $\mathrm{M}^{2+}$ & 2.34 & 2.56 & 0.22 \\
Cys 737- $\mathrm{M}^{2+}$ (B conf) & - & 3.28 & - \\
Glu 676- $\mathrm{M}^{2+}$ & 2.01 & 2.50 & 0.49 \\
$\mathrm{HOH}-\mathrm{M}^{2+}$ & - & 2.46 & - \\
& & & \\
Cd & & & \\
Cd 2-Cys 654 & & 2.50 & \\
Cd 3 - Cys 737 (B conf) & & 2.51 & \\
Cd 4 - Glu 676 & & 2.43
\end{tabular}


Figure 1. ncMetE structure. Two views of each representation are shown, with the second view rotated $90^{\circ}$ relative to the first. A. Cartoon representation of ncMetE. The residues are coloured as follows: N-terminal domain, magenta; C-terminal domain, cyan; connecting alpha-helical scaffold, brown. The side chains of the metal binding residues are coloured green.

B. Surface representation of MetE, colored by calculated charge (red: negative, blue: positive)
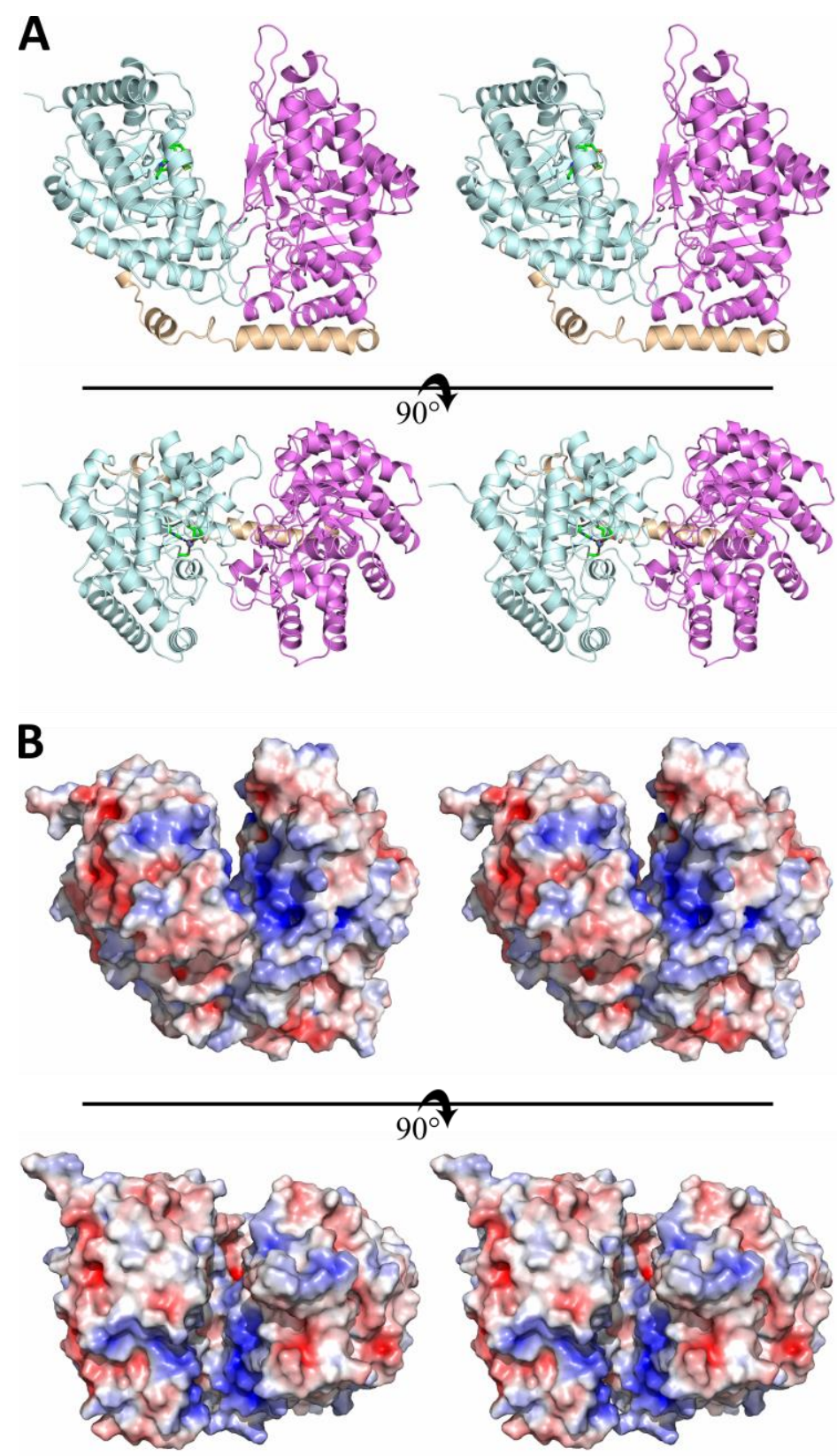
Figure 2. Sequence Conservation in methionine synthases. (A) MetE is shown as a cartoon representation with conserved residues indicated by a stick representation. Residues colored magenta are conserved among all sequences examined (996 sequences including plant, animal, fungi sources). Residues coloured green indicate additional residues conserved among fungi (166 sequences analyzed).

(B) The $N$. crassa MetE sequence is shown, with residues conserved among the fungi sequences analyzed (166) shown in green and residues conserved among all sequences analyzed (996, bacteria, plant, and fungi) shown in magenta. The secondary structure, determined from the $N$. crassa crystal structure presented herein is shown above the protein sequence and coloured blue (N-terminal domain), orange (backbone), or red (C-terminal domain). Cont: indicates all residues interacting with the opposite domain. Blue bars indicate residues that interact in both open and closed conformations, orange bars indicate residues that only interact in the closed conformation, and purple bars indicate residues that only interact in the open conformation. Lig: indicates all residues that are involved in ligand binding. Stars indicate metal binding, triangles indicate $\mathrm{H}_{4} \mathrm{PteGlu}_{3}$ binding, circles indicate homocysteine binding, and boxes indicated residues that bind both substrates. Figure prepared, in part, with ESPript [46].

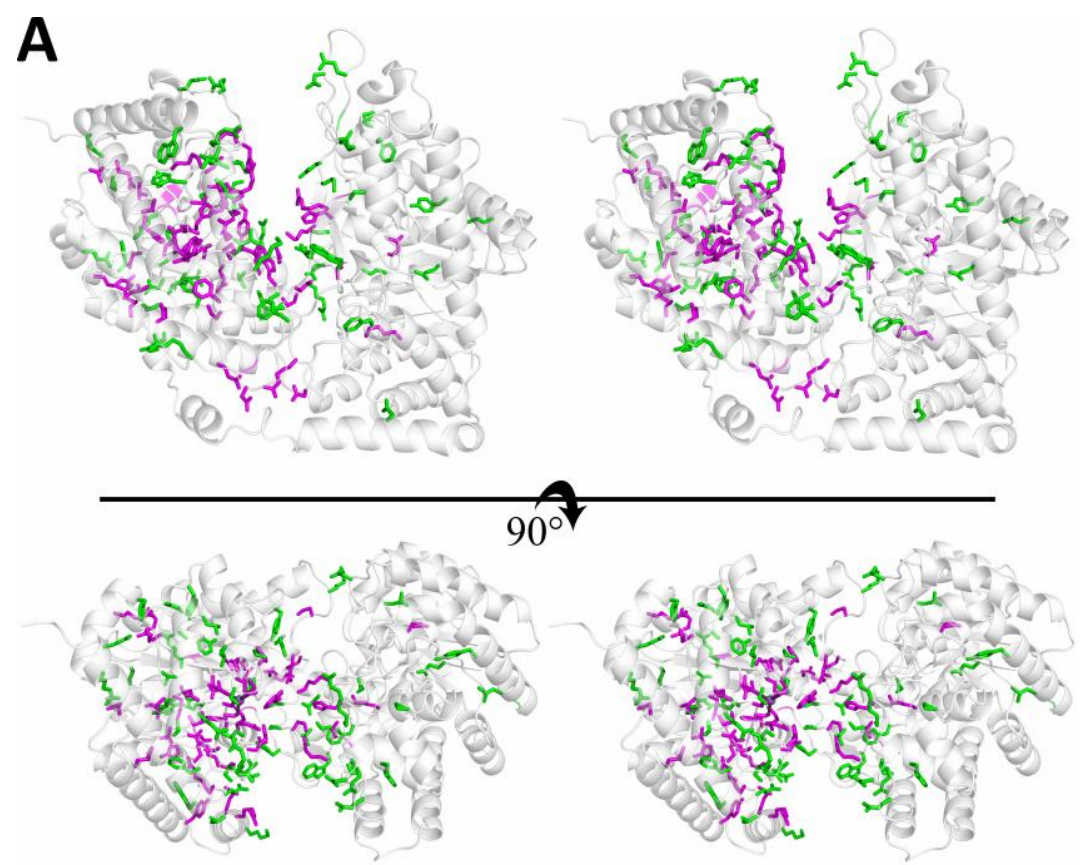




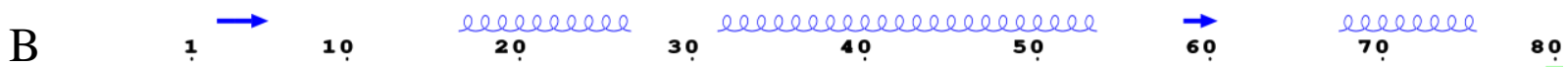
N.crassa MVQSSVLGFPRMGVLRDLKKANEAYWADKISQEALLAEGKRLRLAHWKIQKDAGVDIIPSNDFAHYDHVLDHIQLFNAVP Fungi

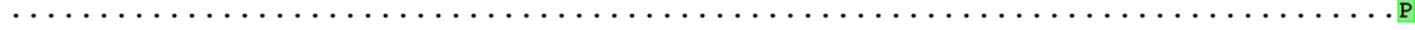
Cont Lig

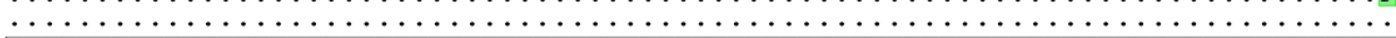

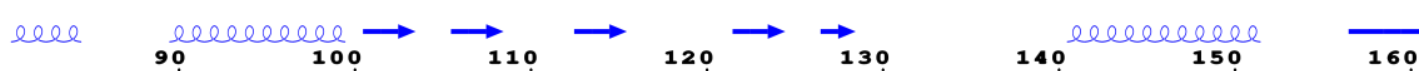
N.crassa ERYTSQKLSPLDEYFAMGRGHQKGGVDVPALEMVKWFD S

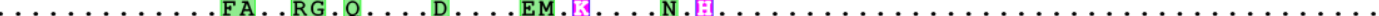

All

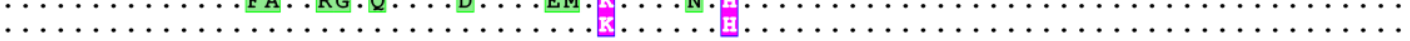
Cont
Lig

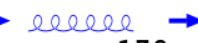

$\Lambda \Delta$

170

180 rerebereceleberele

$\mathbf{2 1 0}$ a 2

$\mathbf{2 2 0}$ lebelebel hel 230

N.crassa VGPVSFLALGKADRGSSVDPITLLDKLVPVYVELLKQLKAAGAESVQIDGPVIVFDLRPEVKAAFKPAYEAIAAAGDAVP

Fungi

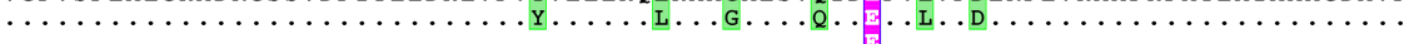

Cont

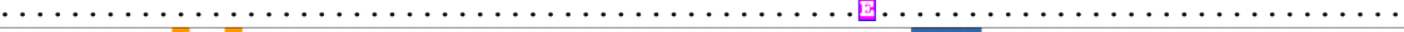

Lig

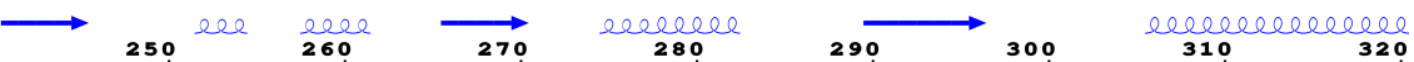

N.crassa KVVVATYFGDIVHNF DVLPAF SGAAGLHVDLVRNPEQLEPVLKQLGPNQ I LSAGVVDGRNI WKNDFAKSLE I LQTAVKAL

Fungi.

Cont

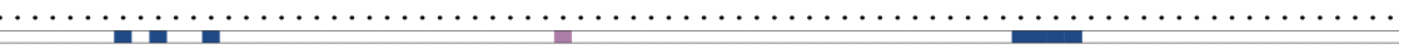
Lig

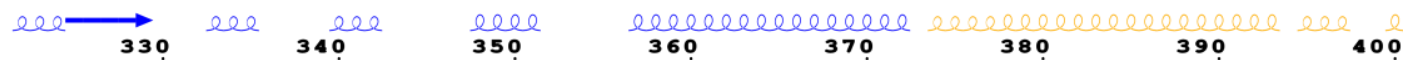
N.crassa GSERVIVATSSSLIHTPHTLASEKKLPSDVYEWFSFAVEKKVKEVATLAKAVTEPEAVKAELEANAAAIKARTDSKRTNDP

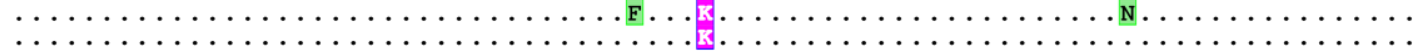

ring

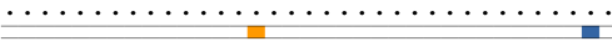

Lig

4104040404090

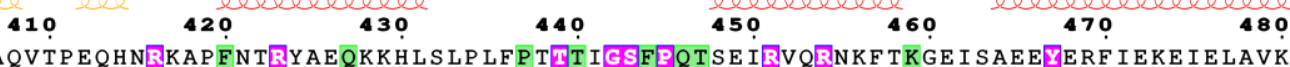
N.crassa AVKERQAQVTPEQHNRKAPFNTRYAEQKKHLSLPLFPTTT IGSFPQTSEIRVQRNKFTKGEISAEEYERFIEKEIELAVK Fungi

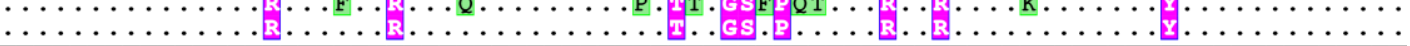
Lig eeees

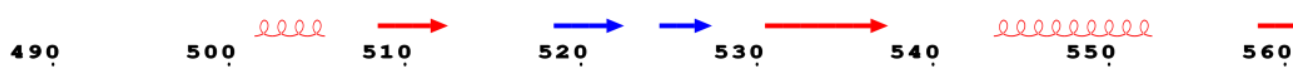

N. crassa Fungi I DE LD LDVYVHGEP GRNDMVQYFGERLNGYVF T T HAWVQSY GSRCVRPP I I VGDI SRPAPMTVKE SKYAAS I SKKPMKG

500

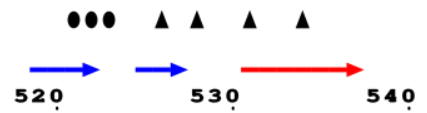

550

560

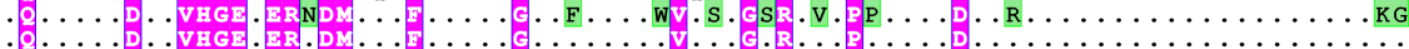
Cont Lig
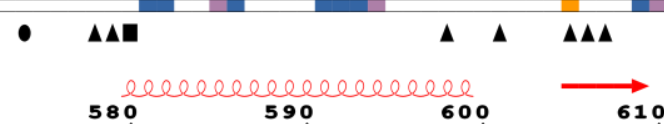

620.6060

N.crassa

Fungi

MLTGEVTCLRWSFPRVDVHQSVQCQQLALALRDEVVDAEKNG I YVIQVDFPALREGLELRKGQEREAYLKWAVDSFKLAT

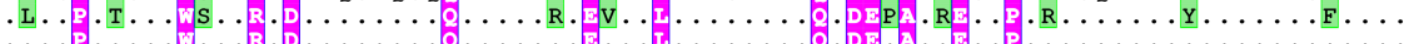

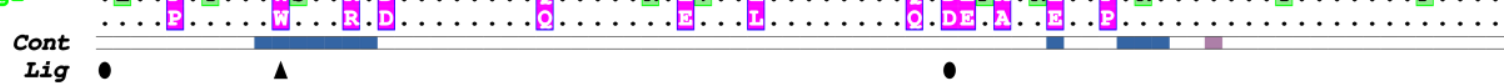

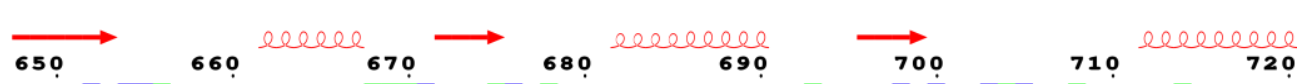
N. crassa AGVENSTQIHSEFCYSEFQDFFHAIAALDADVLSIENSKSDAKLLKVFIDEEYPRHIGPGVYDIFSPRVPTLEEFKQRIE Fungi

11 $\ldots \ldots \ldots \ldots$. CYS . . . . . . LDAD . . II.S . . . . . . . . . . . . . . . .

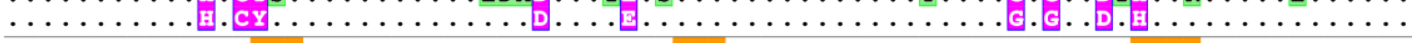

Lig

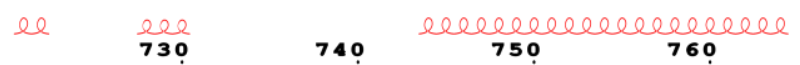

N.crassa EMLAYLKPEQLWINPDCGLKKTRKWDEVKGALSHMVEAAKYFREKYANKA

Fungi

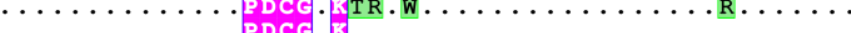

All

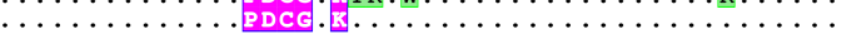


Figure 3. Stereoscopic views of the MetE metal binding site. A. The $\mathrm{Zn}^{2+}$ replete enzyme, showing $\left|\boldsymbol{F}_{\boldsymbol{o}}\right|-\left|\boldsymbol{F}_{\boldsymbol{c}}\right|$ electron density contoured at 3 sigma. B. The $\mathrm{Cd}^{2+}$ replete enzyme, showing $\left|\boldsymbol{F}_{\boldsymbol{o}}\right|-\left|\boldsymbol{F}_{\boldsymbol{c}}\right|$ electron density contoured at 3 sigma. C. The $\mathrm{Cd}^{2+}$ replete enzyme, showing the supermetalation at the active site. The electron density is from the anomalous difference map, contoured at 7 sigma.

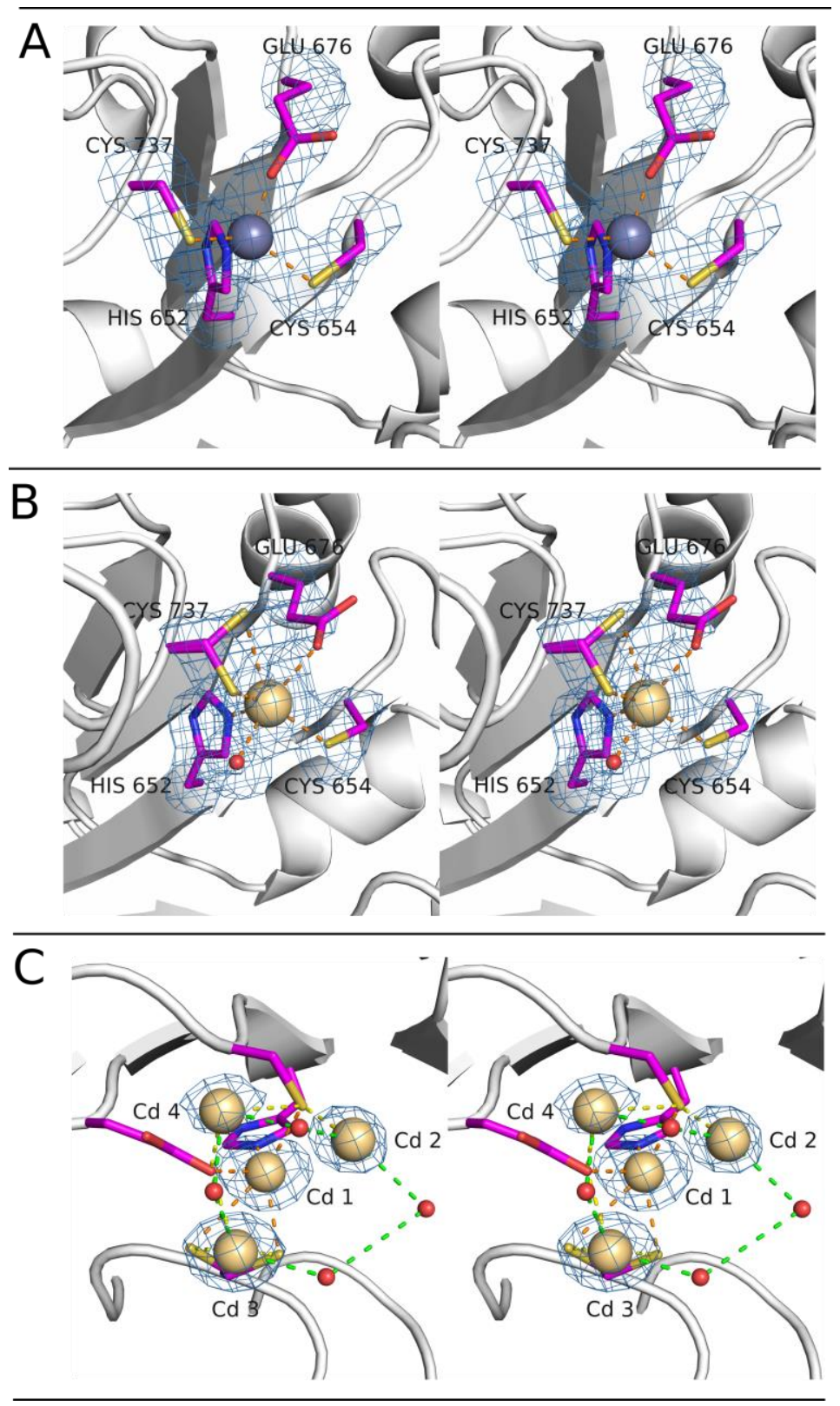


Figure 4. The folate binding site. The complete ncMetE structure is shown in grey as a cartoon representation, with the cleft structure colored orange (enlargement shown on Right). The side chains are shown for those residues interacting with the substrate. Residues conserved in all species examined are represented by side chains colored magenta, residues conserved in all fungal species examined are coloured green, and residues not found to be conserved are represented by cyan. Structural variation in the cleft region of the folate site among the MetE crystallized from the indicated species is shown at the bottom of the figure with a cartoon representation and coloured by temperature factor. Blue indicates a low temperature factor, red a high temperature factor. Undefined residues are represented by blanks. For each species, the best defined connector was selected: N. crassa (4ZTX), C. albicans (3PPG), S. mutans (3L7R), T. maritima (1XDJ), and A. thaliana (1U22).
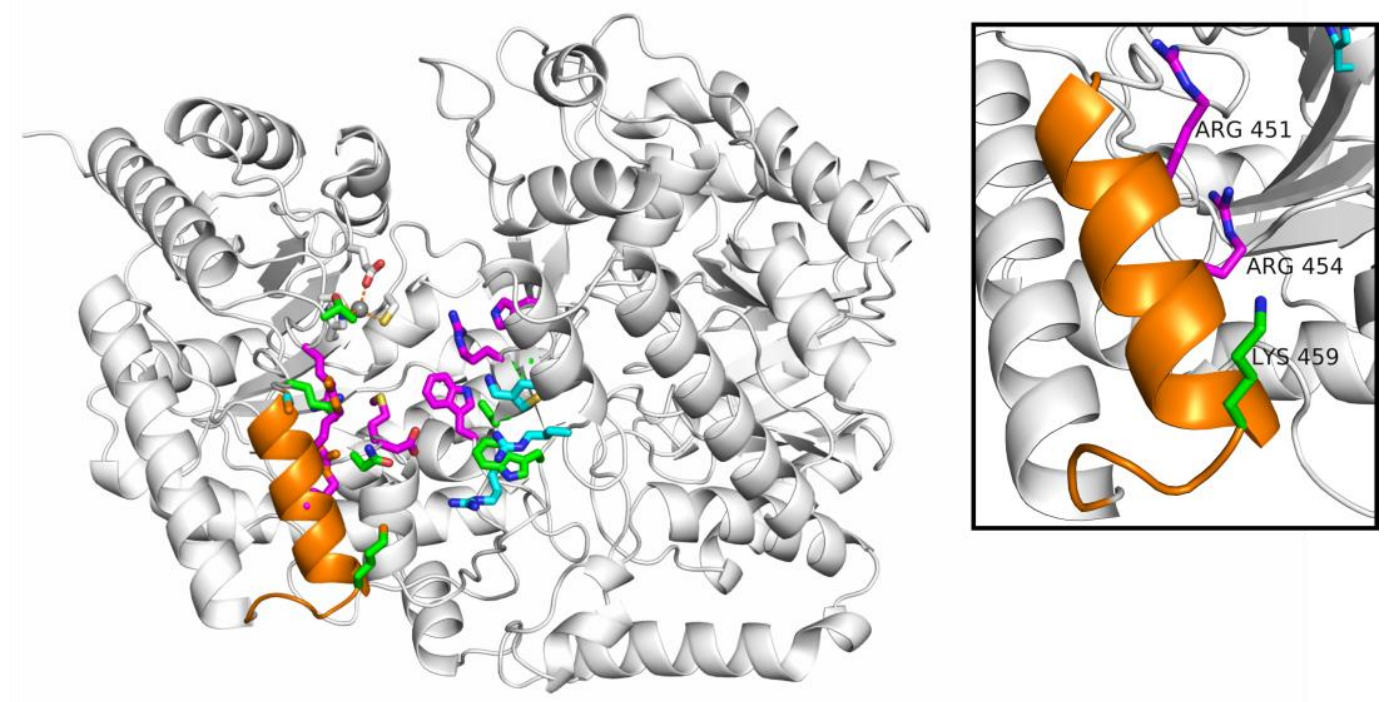

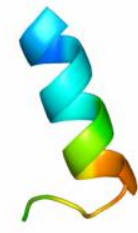

N. crassa

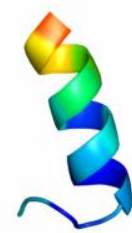

C. albicans

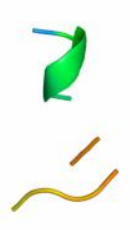

S. mutans

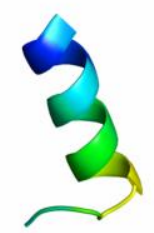

T. maritima

A. thaliana 
Figure 5. Conserved residues associated with the $\alpha$-helical domain connector. The complete $N$. crassa structure is shown in grey as a cartoon representation, while the $\alpha$-helical domain connector is coloured orange. The side chains of residues that are in this structure or interact with it, and are conserved among all species examined are shown and coloured magenta. Inset diagrams show conserved residues involving either the center (A) or $\mathrm{C}$ terminal (B) of the connector.
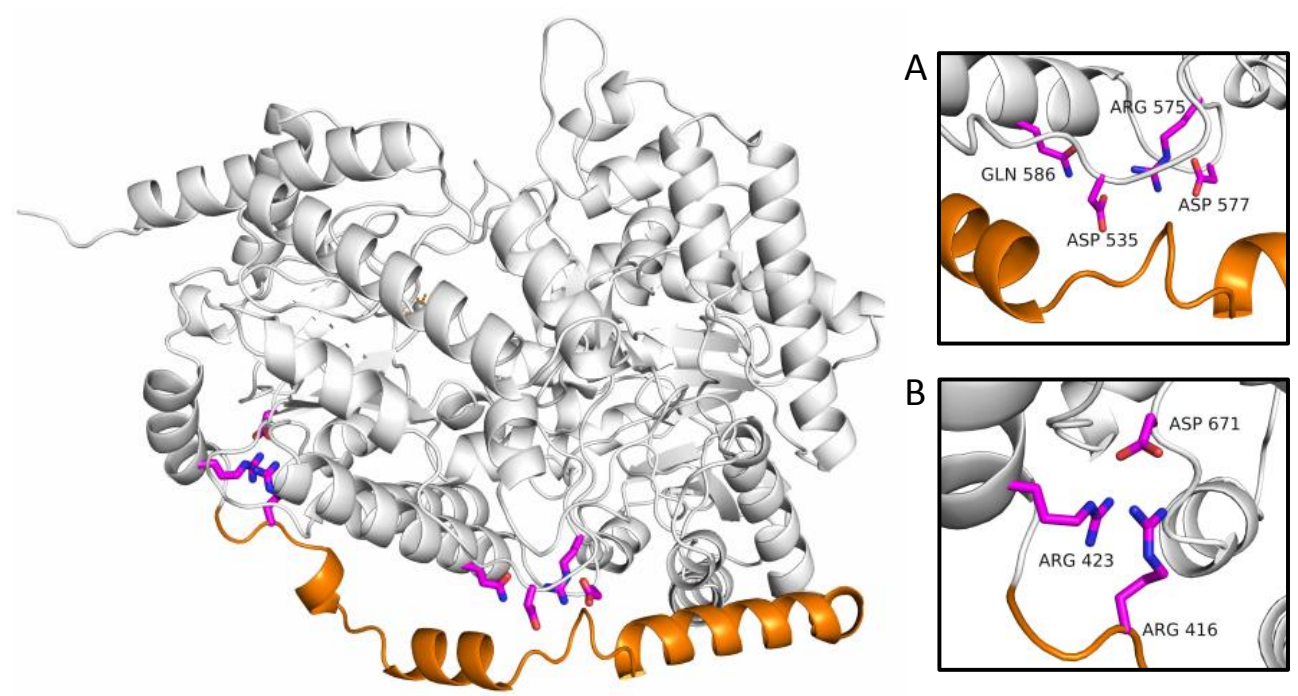
Figure 6. The central cleft and mobile loop. (A) The protein backbone of N. crassa MetE in the area around the central cleft is shown as a grey cartoon, while the mobile loop is shown with a stick representations and coloured orange Additionally, side chains of residues that make interactions upon domain closure are shown with residues conserved in all species examined colored magenta, residues conserved in all fungal species examined coloured green, and residues not found to be conserved are colouredcyan. (B) A comparison of the mobile loop length in currently reported MetE structures. The amino acid backbone from the N. crassa structure is shown as a cartoon in the background. All side chains are omitted. Green=C. albicans $(3 \mathrm{PPH})$, Orange $=N$. crassa $(4 \mathrm{ZTX})$, Blue $=S$. mutans $(3 \mathrm{~L} 7 \mathrm{R})$, Magenta $=A$. thaliana $(1 \mathrm{U} 1 \mathrm{H})$, Yellow $=T$. maritime (3BQ5).
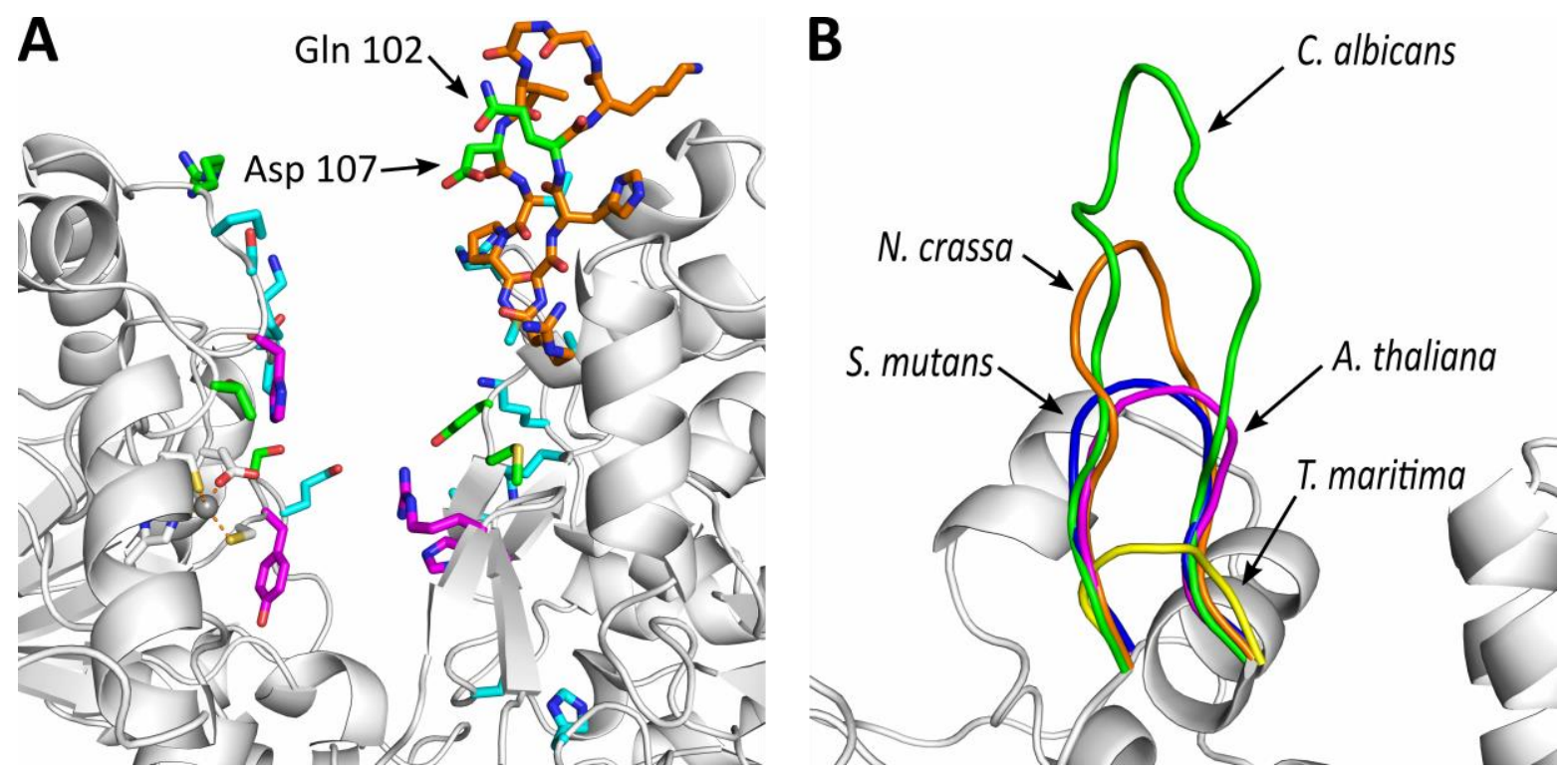